\title{
Effect of Implementing a Designed Nursing Protocol on Nurses' Knowledge and Practice Regarding Epileptic Patients Outcomes
}

\author{
Marrwa A. El-Masry, Zienab A. Mohammad, Ghaydaa A.Shehata, Hala M.Ghanem \\ Demonstrator in Adult Nursing Department, Faculty of Nursing, Assiut University, Egypt \\ Professor and Head of Adult Nursing Department, Faculty of Nursing , Assiut University , Egypt \\ Assistant Professor of Neurological Department, Faculty of Medicine, Assiut University, Egypt \\ Assistant Professor of Adult Nursing Department, Faculty of Nursing , Assiut University, Egypt
}

\begin{abstract}
:
Epilepsy is a brain disorder in which clusters of nerve cells, or neurons, in the brain sometimes signal abnormally. Neurons normally generate electrochemical impulses that act on other neurons, glands, and muscles to produce human thoughts, feelings, and actions. In epilepsy, the normal pattern of neuronal activity becomes disturbed, causing strange sensations, emotions, and behavior, or sometimes convulsions, muscle spasms, and loss of consciousness: More than 2 million people in the United States about 1 in 100 have experienced an unprovoked seizure or been diagnosed with epilepsy. For about 80 percent of those diagnosed with epilepsy, seizures can be controlled with modern medicines and surgical techniques. However, about 25 to 30 percent of people with epilepsy will continue to experience seizures even with the best available treatment. The nurse plays a critical role in reducing complications of this method .The aim of the present study is 3 folds: first is to assess nurse's knowledge and practice regarding epileptic patients, design nursing protocol for nurses working with epileptic patient, and evaluate the effect of implementing the designed nursing protocol on nurse's knowledge and practice regarding epileptic patients. Four hypotheses were formulated: (1) the post mean knowledge scores of nurses who will be exposed to designed nursing protocol will be higher than their pre mean knowledge scores. (2) The post mean practice score of nurses who will be exposed to designed nursing protocol will be higher than their pre mean practice scores. (3) The incidence of complications during seizure for epileptic patient cared by nurses after protocol implementation will be lesser than that developed pre protocol implementation. (4) A positive relationship will exist between knowledge and practice score obtained by nurses receiving the designed nursing protocol. Research design: aquasi-experimental research design was utilized in this study on a convenient sample of 35 nurses and 30 Adult conscious patients with epilepsy, who are aged from 18 to 65 years from both sexes, agree to participate in the study. This study was conducted in the in neurological department at Assiut University Hospital. Tools utilize for data collection were a) Questionnaire sheet. .b) Observation checklist sheet. c) Patient assessment sheet. d) Construction of designed nursing protocol. Results: The first and the second hypotheses were supported as a good improvement in the mean knowledge \& practice scores were found after the implementing of designed nursing protocol. The third hypothesis was supported, as epilepsy complications were improved after protocol implementation. The fourth hypothesis were not able to extract the statistical significance of the relationship between knowledge and nursing practices before and after the study due to the result is one and zero. Conclusion: patient with epilepsy exposed for several complications. Improving nurses' knowledge and practice can favorable affect the incidence of these complications. Recommendation: Nurses in need for in-services training programs and refreshing courses to improve their knowledge which will reflect into their practice while working with epileptic patients.
\end{abstract}

\section{Key Words: Epileptic Patients, Knowledge ,Practice ,Nurses.}

\section{Introduction:}

Epilepsy is an abnormal electrical disturbance in one or more areas of the brain. Epilepsy is defined as the condition of unprovoked, recurrent seizure. A seizure is an episode of abnormal and excessive discharge of cerebral neurons. It can result in sensory, motor, or behavioral activities, and can be associated with changes in the level of consciousness (Stafstrom and Rho, 2004 and Fontain and Hudak, 2005).

In Egypt, the prevalence was estimated to be 6.98/1000 (El Tallawy et al., 2010).Epilepsy affect more than 2 million people in United States, with more than 50,000 to 100,000 new cases reported annually. In united states the prevalence of seizures is approximately 5 to 10 cases per 1000 person in general population; the life time risk of developing epilepsy in one's life time is between $3 \%$ and 5\%.(Buttaro and Bailey, 2008)

The most common complications of epilepsy are divided into physical and systematic complications. Physical complications include injuries, aspiration, fractures, biting tongue, drowning due to respiratory arrest, aspiration and Falling from 
height. A patient may sustain direct trauma or may fall during seizure, but this is usually as a result of the loss of consciousness that occurs during seizure (American Academy of Pediatrics, 2003).

Systematic complications include status of epilepticus, poor controlled epilepsy, permanent brain damage and respiratory arrest (American Academy of Pediatrics, 2003). Nurse's role toward epileptic patient is divided into three steps: before seizures, during seizures and after seizures. The aim of any epilepsy nurse intervention is rapid and complete control of seizures without or minimum complications and antiepileptic drugs (AED) side effects. (Hosking, 2004).

Significance of the study:

From the researchers' clinical experience it has been observed that epileptic patients during seizure are exposed to numerous attended risks and complications. Nurses are the largest group of workers; in addition, they have close and continuous contact with patient. Therefore, they are uniquely placed to incorporate preventive and promote strategies in the day - to - day care they provide. So, they should have knowledge, good attitude and being skillful in dealing with this complication.

\section{The aims of the study:}

1. Assess nurses' knowledge and practice regarding epileptic patients.

2. Design nursing protocol for nurses working with epileptic patients.

3. Evaluate the effect of implementing the design nursing protocol on nurses' knowledge and practice regarding epileptic patients.

\section{Hypothesis:}

To fulfill the end of the study the following research hypotheses were formulated:

1. The post mean knowledge scores of nurses who will exposed to designed nursing protocol will be higher than their per mean knowledge scores.

2. The post mean practice scores of nurses who will exposed to design nursing protocol will be higher than their pre mean performance scores.

3. The incidence of complications during seizure for epileptic patient cared by nurses after protocol implementation will lesser than that developed pre protocol implementation.

4. A positive relationship will exist between knowledge and practice score obtained by nurses receiving the designed nursing protocol.

\section{Subjects and Methods:}

Research design: quasi-experimental research design was utilized in this study.

Setting: The study was conducted in neurological department at Assiut University Hospital.

Sample: A convenience sample of all available nurses (about 35 nurses) working in neurological department and who are willing to participate in the study in addition to adult conscious epileptic patients through 6 months period not less than 30 patients after application of the designed nursing protocol.

\section{Tools:}

Tool- I: pre Pre/post test questionnaire sheet for nurses: consisted of three parts:

Part (1): Socio- demographic data for nurses.

Part (2): Nurses' knowledge about epilepsy.

Part (3): Nurses' knowledge about nursing care before, during and after seizure

Tool II: Observation checklist sheet for nurses: It consists of the 23 items:

Part (1): Nursing intervention before epileptic fits. It includes 6 items.

Part (2): Nursing intervention during epileptic fits. It includes 13items.

Part (3): Nursing intervention after epileptic fits. It includes 4 items.

Tool III: Patient's assessment sheet:. It includes 4 items.

Part (1): Socio demographic data about the patient.

Part (2): General assessment.

Part (3): Assessment of each body system.

Part (4): Detailed assessment of expected complications.

Tool IV: Construction of designed nursing

intervention protocol: it included two parts

Knowledge and Practice about blood transfusion.

Scoring system:

For pre/post test questionnaire sheet: 75 degree.

For observation checklist: total score: 23 degree.

Scores more than $75 \%$ were graded as satisfactory of level .Scores $60 \%-75 \%$ were graded as unsatisfactory of level.

Protection of human rights:

Each patient and nurse was informed with the purpose of the study. The investigator emphasized that the participation is voluntary and confidentially and anonymity of subjects will be assured through coding of all data, and protection of the patient from hazard. Verbal consent was obtained from each patient and nurse prior to his/her contribution in the present study. Confidentiality of any obtained information was secured.

Operational design:

This study was carried out in three phases: 


\section{Phase I: Preparatory phase:}

A review of current, past, local and international related literature in the various aspects of the problems was done. This phase ended by a pilot study.

A pilot study:

A pilot study carried out in December 2010 to test the feasibility and practicability of the study tools on $10 \%$ of sample. It had also provided an estimate of time needed to fill out the tools.

\section{Phase II: Implementation phase:}

Data were collected in neurological department at Assiut University Hospital during the period from December /2010 to June/2011. The tools filled through interviewing. The purpose of the study was explained to the nurses prior to answering the questions. The study was carried out at morning, and after noon shifts.

In which official permission was obtained from the head of neurological department to conduct the study. Name of nurses included in the study was obtained from the head nurses of neurological department. At initial interview the researcher introduce of her self to nurses to initiate line of communication, explain the nature and purpose of the training program and filled out questionnaire sheet (tool I) before and after training program implementation to assess theoretical knowledge needs of nurses. Based on this result the researcher was determined the training program contents that was given to them.

Also she/he scheduled with them the teaching sessions for both theoretical and practical parts and the nurses were divided into small groups, each group contains from 4 to5 nurses. The designed nursing protocol has been implemented for nurses in terms of sessions and teaching on the spot during their official working hours. There were a total of 9 sessions for 30 minutes according to their needs. The number of nurses in each session from 4 to 5 nurses. Each session usually started by a summary of what has been taught during the previous sessions and the objectives of the new topics. Feedback and reinforcement of designed nursing protocol was performed according to the nurses needs to ensure their understanding. Giving praise and/or recognition to the interested nurses were emphasized for motivation during the designed nursing protocol implementation.

Observation checklist (tool II) was assessed by the researcher before and after training program implementation. It was assessed the practical skills of each nurse, practical content was constructed based on the observation checklist results.

Also the researcher explained the nature \& purpose of the designed nursing protocol to the selected patients who are willing to participate in the study and filled out the patient assessment sheet (tool III). Each nurse obtained a copy of the designed nursing protocol booklet that included all the training contents. The whole period for designed nursing protocol implementation was 6 month.

\section{Phase III: Evaluation phase:}

The last phase of designed nursing protocol is the evaluation phase. Immediately after protocol implementation the nurses' knowledge and practice has been evaluated by the researcher through filling the tool (I\&II).

\section{Administrative design:}

An official letter was issued from the Dean of the Faculty of Nursing to the Head of neurological department soliciting the necessary approval to conduct the present research. After explained the aim of the study and the program to nurses to obtain their cooperation the researcher was meetings them to explain the objectives and contents of this designed nursing protocol after obtaining the nurse consent for this study.

\section{Data analysis:}

Data collected and analysis by computer program SPSS" ver. 17" Chicago .USA Data expressed as mean, Standard Deviation, number, and Percentage. Using $\mathrm{T}$ - test to determine significant for numeric variable. Using Chi square to determine significant for non-parametric variable.

\section{Results}

Shows that; the majority of nurses $(54.3 \%)$ their age ranged from 20-30 years. (82.9\%) of them were married. (51.4\%) of them had equal or more than 10 years of experience. $(85.7 \%)$ of them were female. $(88.6 \%)$ of them had diploma of nursing. As regard to previously of attended training programs, it was found that $(82.9 \%)$ were not attending training program. 
Table (1): Total mean knowledge scores obtained by nurse's pre and post implementing of designed nursing protocol $(\mathrm{n}=35)$.

\begin{tabular}{|c|c|c|c|c|c|}
\hline & \multicolumn{2}{|c|}{ Pre $(n=35)$} & \multicolumn{2}{|c|}{ Post $(n=35)$} & \multirow{2}{*}{ P-value } \\
\hline & No. & $\%$ & No. & $\%$ & \\
\hline Unsatisfactory & 34 & 97.1 & 0 & 0.0 & \multirow{2}{*}{$0.000 *^{1}$} \\
\hline Satisfactory & 1 & 2.9 & 35 & 100.0 & \\
\hline Mean \pm SD & \multicolumn{2}{|c|}{$29.8 \pm 6.8$} & \multicolumn{2}{|c|}{$69.3 \pm 3.6$} & $0.000 *^{2}$ \\
\hline
\end{tabular}

* Statistical significant difference $(\mathrm{P}<0.05)$

Table (2): Total mean practice scores obtained by nurses pre and post implementing of designed nursing protocol $(\mathrm{n}=35)$.

\begin{tabular}{|c|c|c|c|c|c|}
\hline \multirow{2}{*}{ Practices items } & \multicolumn{2}{|c|}{ Pre $(n=35)$} & \multicolumn{2}{|c|}{ Post $(n=35)$} & \multirow{2}{*}{ P-value } \\
\hline & No. & $\%$ & No. & $\%$ & \\
\hline - Inadequate & 35 & 100.0 & 0 & 0.0 & \multirow{2}{*}{$0.000 *$} \\
\hline - Adequate & 0 & 0.0 & 35 & 100.0 & \\
\hline - $\quad$ Mean \pm SD & \multicolumn{2}{|c|}{$3.26 \pm 2.19$} & \multicolumn{2}{|c|}{$20.31 \pm 2.05$} & $0.000 *^{2}$ \\
\hline
\end{tabular}

* Statistical significant difference $(\mathrm{P}<0.05)$

Table (3): Percentage distribution of epilepsy complications as regarding pre and post implementing designed nursing protocol of the studied patients $(\mathrm{no}=30)$.

\begin{tabular}{|c|c|c|c|c|c|}
\hline \multirow[t]{2}{*}{ Items } & \multicolumn{2}{|c|}{ Pre $(n=30)$} & \multicolumn{2}{|c|}{ Post $(n=30)$} & \multirow[t]{2}{*}{ P-value } \\
\hline & No. & $\%$ & No. & $\%$ & \\
\hline $\begin{array}{l}\text { Physical complications: } \\
\text { Aspiration } \\
\text { Fractures Skull } \\
\text { Fractures Spine } \\
\text { Fractures limbs } \\
\text { Shoulder dislocation } \\
\text { Biting tongue } \\
\text { Biting lip } \\
\text { Biting cheek } \\
\text { Falling from height or on ground }\end{array}$ & $\begin{array}{l}28 \\
0 \\
0 \\
1 \\
0 \\
30 \\
30 \\
30 \\
29\end{array}$ & $\begin{array}{l}93.3 \\
0.0 \\
0.0 \\
3.3 \\
0.0 \\
100.0 \\
100.0 \\
100.0 \\
96.7\end{array}$ & $\begin{array}{l}0 \\
0 \\
0 \\
0 \\
0 \\
2 \\
2 \\
3 \\
3\end{array}$ & $\begin{array}{l}0.0 \\
0.0 \\
0.0 \\
0.0 \\
0.0 \\
6.7 \\
6.7 \\
10.0 \\
10.0\end{array}$ & $\begin{array}{l}0.000^{*} \\
-- \\
-- \\
1.000 \bullet \\
-- \\
0.000^{*} \\
0.000^{*} \\
0.000^{*} \\
0.000^{*}\end{array}$ \\
\hline $\begin{array}{l}\text { Systematic complications: } \\
\text { Status of epilepticus } \\
\text { Poor controlled epilepsy } \\
\text { Permanent brain damage (stroke or other } \\
\text { damage) } \\
\text { Respiratory arrest }\end{array}$ & $\begin{array}{l}27 \\
30 \\
14 \\
4\end{array}$ & $\begin{array}{l}90.0 \\
100.0 \\
46.7 \\
\\
13.3\end{array}$ & $\begin{array}{l}4 \\
8 \\
1 \\
\\
0\end{array}$ & $\begin{array}{l}13.3 \\
26.7 \\
3.3 \\
0.0\end{array}$ & $\begin{array}{l}0.000^{*} \\
0.000^{*} \\
0.000^{*} \\
0.112\end{array}$ \\
\hline
\end{tabular}

- Fisher exact test 
Table (1): Indicates that; the majority of nurses had satisfactory mean knowledge scores in post implementing designed nursing protocol with $(\mathrm{P}<0.000)$.

Table (2) Shows that, a significant difference between nurse's practices in relation to total mean practice scores with p-values 0.000 .

Table (3): revealed that the incidence of epilepsy complications after application of a designed nursing protocol will be lesser than pre implementation of a designed nursing protocol. It was found that of the majority of the study samples having aspiration, biting tongue, biting lip, biting cheek, falling from height or on ground, status of epilepticus and permanent brain damage.

\section{Discussion:}

The discussion will cover the main result findings as follow:

\section{Sociodemographic characteristics of nurses:}

Based on the results of the present study, the majority of the nurses their ages ranged from 20-30 years, married, female, and have diploma of nursing. The majority of them have no in-service training courses related to epilepsy. The majority of them their experiences at the age of 10 years or more.

Chulabhorn.,(2010); in the same line with the current study findings conducted a study in Bangko area of Thailand .Entitled "A Study of Knowledge and Attitude Improvement on Epilepsy among Thai. Physicians and nurses which revealed that two-third of the nurses were between 21 to 40 year-old and more than half were female.

Marquis and Huston (2009): stated that education and training are two components of staff development that occur after an employees' indoctrination (which refers to planned, guided adjustment of employee to the organization and work environment). The staffs' knowledge level and capabilities are a major factor in determining the number of staff required to carry out unit goals. The better trained and more competent the staff, the fewer the staff required, which in turn saves the organization money and rise reproductively.

II. Nurses knowledge and practice regarding epilepsy:

Data collected before the designed nursing protocol implementation (pre-test) showed unsatisfactory level of nurses' knowledge about epilepsy and care with epileptic patients, which reflects the lack in their scientific preparation. The implementation of the designed protocol showed an improvement in the nurses' level of knowledge regarding the care offered to epileptic patients. The findings indicated that a good improvement in the mean knowledge scores after the application of the designed nursing protocol.

So, we can conclude from the data collected and analysis in the present study that all studied nurses weren't properly prepared prior to their working and/or dealing with such epileptic patients and really they got their experience while being there, working and managing the patients in the real life emergency situations.

The results in the present study revealed that, a great improvement in the practice score levels obtained by nurses after the application of the designed nursing protocol. This has been concluded by the presence of significant difference between results of pre-test and post-test. This finding indicated

that skills can be easily improved, especially if linked with their relevant scientific base of knowledge.

Chulabhorn, (2010); in the same line with the current study findings conducted a study in Bangko area of Thailand. Entitled "A Study of Knowledge and Attitude Improvement on epilepsy among Thai Physicians and Nurses" which demonstrated that total knowledge and attitude scores of two separate groups of physicians and nurses were improved with statistical significance after educational course.

Youssef (2007); in the same line with the current study findings conducted a study at the reconstructive microsurgical and grammatology care units in Assiut University Hospital. Entitled "Microvascular free tissue transfer surgeries, Impact of a designed teaching protocol on nurses' knowledge, practices and patient's outcome" which revealed that an improvement in nurses' practice after the attendance at continuing nursing education sessions. Research findings indicated that continued nursing education programs increase knowledge, practice and can also improve attitudes.

\section{III . Assessment of epileptic patients:}

The results of the present study showed that; the majority of patients were male, married, their ages ranged from 18 to 40 years, they have secondary education and more than half of patients are no work and farmer. This study finding was conflict with the study by ( Christensen and et al 2005); stated that no overall gender difference was found in either the epileptic patients.

The result agree with the study of (Shawki, 1996); entitled as" clinico- epidemiologic study of epilepsy in Assiut University" . This revealed that sex distribution of surveyed sample and epileptic patients showed that is higher percentage of male epileptic 
patients in all areas and age groups except in the age period $12<18$ years.

In the relation to material status, it was found that the majority of patients were married this study was in disagreement with (Kim, 2007); who found that the marriage rate among Korean people with epilepsy was about $80 \%$ of expected in general population. It is generally agreed that people with epilepsy are less likely to marry than general population all over the world.

In this respect (Shawki, 1996); in this study found that the highest prevalence rate of epilepsy in married than in single patients in rural areas (9.8/1000 and 6.1/1000 respectively).

As regard analysis of convulsion of the studied patients the present study revealed that half of patients have frequency of epileptic fits daily. These results disagree with the study of (Ahmed, 2004); in this study found that number of seizures in the last month from one to less than ten in nearly threequarters of the subjects.

As regard family history about the epilepsy, the majority of patients were almost having no medical family history. This study finding disagrees with the study of (Ottman, et al., 2011); who reported that family history accounts for among relatives with epilepsy, $90 \%$ of offspring and $80 \%$ of siblings but only $32 \%$ of parents screened positive.

As regard epilepsy complications in the present study it was founded that, the incidence of epilepsy complications after application of a designed nursing protocol was lesser than pre implementation of the designed nursing protocol. The most common complications which occurred pre implementing the designed nursing protocol were a aspiration, biting tongue,

biting lip, biting cheek and falling from height or on ground.

A study that was conducted by (Ahmed ,2004); in the out patient unit of Alexandria Epilepsy center at El-Hadara University hospital. Entitled" Assessment of health-related behaviors among epileptic adult patients" agree with the study which revealed that nearly the largest proportion of the subjects suffered from seizures problems while the others didn't. these seizures problems as biting tongue or lips, wound and injuries, fractures in different sites in the body.

Regarding fractures limbs of the studied patients in the present study it was found that, a few patients suffering from fractures in different sites in the body. This finding disagrees with (Souverein, et al.,2005); This study reviewed 40,000 patients with epilepsy, who were followed for a median of three years. It was determined that the risk of fractures among people with epilepsy was two-fold higher compared with the general population.

Finally, it can be concluded that, the designed nursing protocol for nurses working with epileptic patients has achieved, its objectives by improving nurses' knowledge and practice regarding epileptic patient care. This further was supported by (Porth, 2000); who stated that professional nurses have a large role to play in the minimization and prevention of epilepsy complications and should be clinically well versed in all aspects of the condition, current strategies to address risk minimization and prevention management and advocates for patient safety.

\section{Conclusion:}

Based on the results of the present study, it can be concluded that:

- Nurse's knowledge and practice regarding epileptic patients in neurological department at Assiut university hospital are inadequate. Nurses are potentially capable to improve their knowledge and practice after exposure to designed nursing protocol.

- Implementing the designed nursing protocol on nurse's knowledge and practice regarding epileptic patients shows a significant improvement in nurses' knowledge and practice. Improving nurses' knowledge and practice can favorable affect the incidence of epilepsy complications.

- Epileptic Patients exposed for several complications. These complications include physical complications and Psychological complications. The physical complications include aspiration, fractures skull, fractures spine, fractures limbs, shoulder dislocation, biting tongue, biting lip, biting cheek, falling from height or on ground, status of epilepticus , poor controlled epilepsy, permanent brain damage and respiratory arrest as previously mentioned in the literature and need effective measures to prevent/ reduce this considerable profound problem.

\section{Recommendations:}

Based on results of the present study it can be recommended that:

For nurses:

1. Continued nursing education and inservice training programs on neurological department should be well organized at Assiut University Hospital and equipped with the necessary educational facilities and materials necessary to upgrade the knowledge and skills of practicing 
nurses, which will be reflected on better outcome and service for inpatients.

2. Nurses should add to their routine obligations the regular reading of up-to-date references (periodicals, textbooks, etc.). They should always be encouraged to attend scientific meetings and conferences to keep pace with the rapidly growing wealth of knowledge and practice necessary for proper nursing service.

3. Newly employed nurses in neurological department are required to successfully complete a test of basic knowledge and skills before assuming independent responsibility for patient care.

For patients:

1. Patients are to be provided with sufficient relevant written information to remind them about what they can or can not do to assist them to cope with epileptic fits.

2. The multidisciplinary approach must be used in caring for patients with epilepsy. Available resources should include the patient, the patient's family, the nurse, and other nursing staff.

For administration:

1. Adequate supplies and facilities should be available in the unit.

2. Periodic monitoring of nurses knowledge and practice to evaluate the level of nurses.

3. Orientation program for all newly nurses and in services training programme for experienced nurses about epilepsy, the different types of epilepsy and its complications.

4. The neurological department should have a written policy about the standardized nursing care that should be delivered to every patient in the department.

5. Availability of manual procedures for nurses to be aware of handling any problems that may be arises.

6. Presence and reviewing of patient's records for proper follow up for patient with epilepsy.

\section{References:}

1. Ahmed A.D.,(2004): Assessment of healthrelated behaviors among epileptic adult patients Submitted for fulfillment of the requirements of Master Degree in adult nursing, Faculty of Nursing, Alexandria University.

2. American Academy of Pediatrics., (2003): Report of the Committee on management and complication of epilepsy 26th ed. Elk Grove Village, III: American Academy of Pediatrics.
3. Buttaro T.M and Bailey P.P., (2008): Primary Care, Chapter 213, 3rd ed, Mosby Elsevier, Pp 1077.

4. Christensen J., Kjelden J., M., Andersen H., friis L., M. and Sdenius P.,(2005): Epilepsia, Gender Differences in Epilepsy, volume46,issue 6,P 956, Jun.onlinelibrary.wiley.com/doi/10.1111/j.1528167.2005.51204.x/pdf .

5. Chulabhorn P., H., (2010); A Study of Knowledge and Attitude Improvement on Epilepsy among Thai Physicians and nurses., a study in Bangko area of Thailand.

6. El Tallawy, H.N., Farghaly, W.M., Metwaly, N.A., Rageh, T.A., Shehata,G.A., Elfetoh, N.A., Hegazy, A.M., El-Moselhy, E.A., Rayan,I., Al-Fawal, B.M., Abd Elhamed, M.A., (2010): Door-to-door surveyof major neurological disorders in Al Kharga District, NewValley, Egypt: methodological aspects. Neuroepidemiology 35,185-190.

7. Fontaine, D.K., \& Hudak, C.M., (2005): Critical Nursing: Holistic approach, chapter 35, 5th ed, Lippincott williams and willins, Pp 824.

8. Hosking P., G., (2004); The Specialist Nurse Role in the Treatment of Refractory Epilepsy. Seizure.13(5):303-7.

9. KIM M. K.,(2007): Marital prospects of people with epilepsy among Asians .P13. http://www.neurologyasia.org/articles/3_013.pdf.

10. Marquis L. Bessie \& Huston J. Carol (2009): Leader ship roles \& management functions in nursing, 6th ed., Lippincott, Hong Kong, p. 371 .

11. Ottman R., Barker C., Leibson C., L., Vasoli V., M. and Hauser W., A., (2011): Accuracy of family history information on epilepsy and other seizure disorders, Neurology January 25, 2011 vol. 76 no. 4 390-396. www.neurology.org/content/76/4/390.short.

12. Porth C.,(2000): Pathophysiology: Concepts in altered health states. 5th edition. New York. Lippincott Co.

13. Shawki A., O., (1996):Clinico-epidemologic study of epilepsy in Assiut. Submitted for fulfillment of the requirements of Doctorate Degree in neurology, Faculty of medicine, Assuit University.

14. Souverein PC, Webb DJ and Petri H.,(2005): Incidence of fractures among epilepsy patients: a population-based retrospective cohort study in the General Practice Research Database. Epilepsia 2005;46:304-10. 
15. Stafstorm, C.E., and Rho, J.N., (2004): Epilepsy and ketogenic Diet, Chapter 1, 1st ed, Human press, $\mathrm{Pp} 3$ - 4.

16. Youssef, S., S., (2007): Microvascular free tissue transfer surgeries Impact of a designed teaching protocol on nurse's knowledge, practices and patient's outcome. Submitted for fulfillment of the requirements of Doctorate Degree in Adult Nursing, Faculty of Nursing, Assiut University. 